Research paper

\title{
Synthesis of novel diflunisal hydrazide-hydrazones as anti-hepatitis C virus agents and hepatocellular carcinoma inhibitors ${ }^{\text {ir }}$
}

\author{
Sevil Şenkardeş ${ }^{a}$, Neerja Kaushik-Basu ${ }^{\mathrm{b}}$, İrem Durmaz ${ }^{\mathrm{c}}$, Dinesh Manvar ${ }^{\mathrm{b}}$, \\ Amartya Basu ${ }^{\mathrm{b}}$, Rengül Atalay ${ }^{\mathrm{d}}$, S.. Güniz Küçükgüzel ${ }^{\mathrm{a}, ~ *}$ \\ a Marmara University, Faculty of Pharmacy, Department of Pharmaceutical Chemistry, Haydarpaşa, 34668, Istanbul, Turkey \\ ${ }^{\mathrm{b}}$ Rutgers-New Jersey Medical School, Department of Microbiology, Biochemistry and Molecular Genetics, Newark, NJ 07103, USA \\ ${ }^{\mathrm{c}}$ Bilkent University, Department of Molecular Biology and Genetics, 06800, Bilkent Ankara, Turkey \\ d Cancer Systems Biology Laboratory, Graduate School of Informatics Middle East Technical University, ODTU, 06800, Ankara, Turkey
}

\section{A R T I C L E I N F O}

\section{Article history:}

Received 24 March 2015

Received in revised form

23 October 2015

Accepted 25 October 2015

Available online 28 October 2015

\section{Keywords:}

Diflunisal

Hydrazide-hydrazone

Hepatitis C

Hepatocellular carcinom

Antiviral

\begin{abstract}
A B S T R A C T
Hepatitis $\mathrm{C}$ virus (HCV) infection is a main cause of chronic liver disease, leading to liver cirrhosis and hepatocellular carcinoma (HCC). The objective of our research was to develop effective agents against viral replication. We have previously identified the hydrazide-hydrazone scaffold as a promising hepatitis $\mathrm{C}$ virus (HCV) and hepatocelluler inhibitor. Herein we describe the design a number of $2^{\prime}, 4^{\prime}-$ difluoro-4-hydroxy- $N^{\prime}$-(arylmethylidene) biphenyl-3-carbohydrazide (3a-t) as anti-HCV and anticancer agents. Results from evaluation of anti-HCV activity indicated that most of the synthesized hydrazone derivatives inhibited viral replication in the Huh7/Rep-Feo1b and Huh 7.5-FGR-JCI-Rluc2A reporter systems. Antiproliferative activities of increasing concentrations of $2^{\prime}, 4^{\prime}$-difluoro-4-hydroxy- $N^{\prime}-(2-$ pyridyl methylidene)biphenyl-3-carbohydrazide $\mathbf{3 b}$ and diflunisal $(2.5-40 \mu \mathrm{M})$ were assessed in liver cancer cell lines (Huh7, HepG2, Hep3B, Mahlavu, FOCUS and SNU-475) with sulforhodamine B assay for $72 \mathrm{~h}$. Compound $\mathbf{3 b}$ with 2-pyridinyl group in the hydrazone part exhibited promising cytotoxic activity against all cell lines with $\mathrm{IC}_{50}$ values of $10,10.3416 .214 .74,9.29$ and $8.33 \mu \mathrm{M}$ for Huh7, HepG2, Hep3B, Mahlavu, FOCUS and SNU-475 cells, respectively, and produced dramatic cell cycle arrest at SubG1/G0 phase as an indicator of apoptotic cell death induction.
\end{abstract}

() 2015 Elsevier Masson SAS. All rights reserved.

\section{Introduction}

Hepatitis $\mathrm{C}$ virus (HCV) is an enveloped virus that is classified in the hepacivirus genus of the Flaviviridae family [1]. The virus RNA genome encodes a polyprotein, which is posttranslationally processed by host and virus proteases into 10 mature proteins, of which 4 are structural proteins (C, E1, E2, and p7) and 6 nonstructural proteins (NS2, NS3, NS4A, NS4B, NS5A, and NS5B) [2]. $\mathrm{HCV}$ is a worldwide infectious pathogen that causes chronic liver diseases, including hepatic fibrosis, hepatic cirrhosis and hepatocellular carcinoma (HCC) [3]. Until recently, HCV-infected patients were treated with a combination of pegylated interferon- $\alpha$ (IFN- $\alpha$ ) and the nucleoside analog ribavirin. However, this therapy had

\footnotetext{
This work was partly presented at the 4th International Meeting on Pharmacy and Pharmaceutical and Sciences, İstanbul-Turkey, 18-23 September, 2014.

* Corresponding author.

E-mail address: gkucukguzel@marmara.edu.tr (Ş.G. Küçükgüzel).
}

limited effectiveness especially in context of patients infected with HCV genotype 1. Furthermore, treatment with interferon is associated with numerous side effects. Recently, new anti-HCV therapies utilizing the direct acting antivirals (DAAs) against the viral proteins HCV NS3-4A protease and NS5B polymerase have been approved. These therapy although more promising have complicated dosing regimens limiting patient compliance [4-7]. Further, the selection of HCV drug resistant variants continues to remain a concern $[8,9]$. On the other hand, acute and chronic liver diseases that are caused by an infection with hepatitis-C virus (HCV), such as hepatocellular carcinoma and liver cirrhosis have received much attention over the past decade. Recently, HCV is believed to act as carcinogen by virtue of the increased risk of hepatocellular carcinoma among persistently infected patients with chronic active hepatitis. Therefore, it is important to develop new, safer and even more effective agents against HCV infection and resistance emergence.

Diflunisal derivatives [10-14] (Fig. 1) have been reported to possess diverse biological activities such as anticancer, anti-HCV, 
<smiles>C/C=N\NC(=O)c1cc(-c2ccc(F)cc2F)ccc1O</smiles><smiles>O=C1CSC([Tl])N1</smiles><smiles>O=C(NC(=O)N1C(=O)CSC1c1ccccc1F)c1cc(-c2ccc(F)cc2F)ccc1O</smiles><smiles>Cc1cc(C)n(C(=O)c2cc(-c3ccc(F)cc3F)ccc2O)n1</smiles>

Fig. 1. Diflunisal derivatives. anticonvulsant, antimicrobial and anti-inflammatory properties [15]. In medicinal chemistry, the presence of a hydrazide-hydrazone group in compounds, has usually led to the development of clinically relevant biological molecules with antimicrobial, anticancer [16,17] and antiviral properties [18].

Recently, our group reported the synthesis of novel hydrazide-hydrazone derivatives and their HCV NS5B inhibition effects [19] (Fig. 2).

Diflunisal is a difluorophenyl derivative of salicylic acid and a non-steroidal drug with analgesic, anti-inflammatory and antipyretic properties. It is a peripherally-acting non-narcotic analgesic drug which functions as a prostaglandin synthase inhibitor. In animals, prostaglandins sensitize afferent nerves and potentiate the action of bradykinin in inducing pain. Since prostaglandins are known to be among the mediators of pain and inflammation, the mode of action of diflunisal may be due to a decrease of prostaglandins in peripheral tissues.

Herein, we report our ongoing efforts towards development of more effective anti-HCV agents. We focused our attention on the<smiles>CC(C(=O)N/N=C/c1ccc(F)cc1)c1ccc(-c2ccccc2)c(F)c1</smiles><smiles>CCc1ccc(/C=N/NC(=O)C(C)c2ccc(-c3ccccc3)c(F)c2)o1</smiles>

Fig. 2. Hydrazones of anti-HCV activity. hydrazide-hydrazone moiety. Thus, a new series of hydrazide-hydrazone derivatives were synthesized from diflunisal and evaluated for their anti-HCV activity in vitro and anticancer activity against hepatocellular cancer cell lines.

\section{Results and discussion}

\subsection{Chemistry}

Methyl 2',4'-difluoro-4-hydroxybiphenyl-3-carboxylate [1] was prepared by the reaction of diflunisal and methanol in the presence of a few drops of concentrated sulfuric acid. 2',4'-Difluoro-4hydroxybiphenyl-3-carboxylic acid hydrazide [2] was prepared by heating hydrazine-hydrate and [1] in methanol [10]. After condensing hydrazide with substituted aldehydes in ethanol, novel $2^{\prime}, 4$ '-difluoro-4-hydroxy- $N$ '-(arylmethylidene) biphenyl-3-carbo hydrazide [3a-t] were obtained. The synthesis of novel series of hydrazide-hydrazones 3a-t was performed as outlined in Scheme 1. All synthesized compounds were checked for purity using TLC and HPLC-UV/DAD and were characterized by their melting points, ${ }^{1} \mathrm{H}$ NMR, ${ }^{13} \mathrm{C}$ NMR and HR-MS spectral data.

The FT-IR spectra of hydrazones showed absorption bands at $1583-1614 \mathrm{~cm}^{-1}$ due to $\mathrm{C}=\mathrm{N}$ groups. Moreover, $\mathrm{C}=\mathrm{O}$ absorption<smiles>COC(=O)c1cc(-c2ccc(F)cc2F)ccc1OS(=O)(=O)OCc1ccc(O)c(C(=O)O)c1</smiles><smiles>NNC(=O)c1cc(-c2ccc(F)cc2F)ccc1O</smiles>

Scheme 1. The synthetic route for the preparation of the target compounds (3a-t). 
bands were observed between 1633 and $1647 \mathrm{~cm}^{-1}$. The absorption bands associated with other functional groups appeared in the expected regions. In the ${ }^{1} \mathrm{H}$ NMR spectra of all hydrazones, the signal representing the azomethine $\mathrm{CH}$ protons appeared at 8.41-9.11 ppm, whereas a $\mathrm{D}_{2} \mathrm{O}$-exchangeable signal due to $\mathrm{NH}$ amidic proton $(-\mathrm{CONHN}=\mathrm{CH}-)$ and $-\mathrm{OH}$ resonated at 11.78-12.28 ppm. The other protons appeared at the expected chemical shifts and integral values. ${ }^{13} \mathrm{C}$ NMR spectrum of $\mathbf{3 a - t}$ showed the absence of the $\mathrm{C}=\mathrm{O}$ signal at $\delta 164.59-165.38 \mathrm{ppm}$ and $-\mathrm{N}=\mathrm{CH}$ 144.70-149.32 ppm. Besides, the heteronuclear multiple bond correlation (HMBC) spectrum of compound 30 also confirmed the detection of long-range ${ }^{1} \mathrm{H}-{ }^{13} \mathrm{C}$ couplings. HR-EI (for $\mathbf{3 j}$ and $\mathbf{3 o}$ ) and DART-MS (for 3d and 3s) confirmed the molecular weights and empirical formulae of compounds with less than $1 \mathrm{mmu}$ bias between calculated and experimental $\mathrm{m} / \mathrm{z}$ values of either molecular or fragment ions. The major fragmentation pattern involved the cleavage of the $\mathrm{CONH}-\mathrm{NH}=$ amide bond $m / z 249$. The species $m / z$ 232 and $m / z 177$ in compounds (3j, 3o) may results from loss of $-\mathrm{NH}_{2}$ and subsequent loss of $\mathrm{CO}$ in the phenyl ring.

\subsection{Biological evaluation}

\subsubsection{Anti-HCV effect of diflunisal hydrazide-hydrazones}

In order to identify potential anti-HCV agents, we employed two reporter cell lines, Huh7/Rep-Feo1b and Huh7.5-FGR-JC1-Rluc2A (Table 1 ). These cells carry the autonomously replicating HCV RNA of genotype $1 \mathrm{~b}$ and $2 \mathrm{a}$ in the firefly and Renilla luciferase reporters, respectively [20-24]. Therefore levels of their respective luciferase serves as an indicator of HCV RNA replication. The effect of the compounds on cell viability was investigated in the Huh7.5 parental cells by the MTS assay and employed to compute $50 \%$ cytotoxicity values $\left(\mathrm{CC}_{50}\right)$ (Table 1$)$.

The nineteen compounds displayed a wide range of cytotoxicity in the parental Huh7.5 cells. Among these $\mathbf{3 f}, \mathbf{3 g}, \mathbf{3 i}, \mathbf{3 k}, \mathbf{3 n}, \mathbf{3 o}, \mathbf{3 p}$ and 3t exhibited $\mathrm{CC}_{50}<50 \mu \mathrm{M}$, suggesting that these compounds may be detrimental to cell viability. In contrast, 3c, 3m and $\mathbf{3 r}$ with $\mathrm{CC}_{50}>200 \mu \mathrm{M}$, proved to be the least cytotoxic. The remaining compounds displayed cytotoxicity in the interim range with compounds 3a, 3d, 3e, $\mathbf{3 h}$, and $\mathbf{3 1}$ exhibiting $\mathrm{CC}_{50}>50 \mu \mathrm{M}$, while $\mathbf{3 b}, \mathbf{3 j}$ and 3s displaying $\mathrm{CC}_{50}>100 \mu \mathrm{M}$.

We next screened the compounds at $50 \mu \mathrm{M}$ concentration for their anti-HCV activity. With the exception of 3d which exhibited $33 \%$ and $23 \%$ inhibition against $1 \mathrm{~b}$ and $2 \mathrm{a}$ replicon reporters respectively, all others displayed $\geq 58 \%$ inhibition. Notably, all compounds with the exception of $\mathbf{3 g}, \mathbf{3 h}, \mathbf{3 r}$ and $\mathbf{3 a}$ exhibited higher inhibition of $2 \mathrm{a}$ replicons relative to $1 \mathrm{~b}$, suggesting higher antiviral potency of the compounds against HCV genotype $2 \mathrm{a}$. Compounds exhibiting $\geq 70 \%$ inhibition against $1 \mathrm{~b}$ replicon and $\mathrm{CC}_{50} \geq 50 \mu \mathrm{M}$ were further characterized in terms of their $\mathrm{EC}_{50}$ values. This resulted in the identification of 6 compounds $\mathbf{3 a}, \mathbf{3 b}, \mathbf{3 c}$, 3h, $\mathbf{3 m}$ and $\mathbf{3 r}$ which met this cut-off criteria and displayed $\mathrm{EC}_{50}$ values ranging between 3.9 and $16.5 \mu \mathrm{M}$ and selectivity index (SI) between 3 and 25. Among these, compound 3b, 2',4'-difluoro-4hydroxy- $N$ '-[(pyridin-2-yl)methylidene]biphenyl-3-

carbohydrazide appeared the most promising with an $\mathrm{EC}_{50}$ of 3.9 and SI $>25.6$.

To identify the mechanism of action of these compounds against $\mathrm{HCV}$, we investigated if the compounds target HCV NS5B. Towards this end, we screened the compounds in vitro for their ability to inhibit NS5B RdRp activity. As seen in Table 1, the compounds displayed no inhibition or $\leq 18 \%$ inhibition of HCV NS5B, thus suggesting that the compounds function through a mechanism other than targeting HCV NS5B.

Further studies are in progress to optimize the structures of hydrazide-hydrazone derivatives with the aim of increasing their anti-HCV potency.

\subsubsection{Anticancer activity of compound $\mathbf{3} \boldsymbol{b}$ against liver cancer cell} lines

In order to determine the potential anticancer activity of the obtained diflunisal hydrazide hydrazone $\mathbf{3 b}$ and diflunisal, we evaluated their cytotoxic activity on liver cancer cell lines (Huh7, HepG2, Hep3B, Mahlavu, FOCUS and SNU-475) with the sulforhodamine B assay $(2.5-40 \mu \mathrm{M})$ for $72 \mathrm{~h}$ as described before [25]

Table 1

Anti-HCV activity of diflunisal hydrazide-hydrazones (3a-t).

\begin{tabular}{|c|c|c|c|c|c|c|}
\hline \multirow[t]{2}{*}{ Comp. } & \multirow[t]{2}{*}{$\mathrm{CC}_{50}(\mu \mathrm{M})^{\mathrm{a}}$} & \multirow[t]{2}{*}{ Huh7.5-FGR-JC1-Rluc2A (\% inhibition) ${ }^{\mathrm{b}}$} & \multicolumn{3}{|c|}{ Huh7/Rep-Feo1b } & \multirow[t]{2}{*}{ Anti-NS5B Activity (\% Inh., $50 \mu \mathrm{M})^{\mathrm{f}}$} \\
\hline & & & $(\text { Inhibition } \%)^{c}$ & $\mathrm{EC}_{50}(\mu \mathrm{M})^{\mathrm{d}}$ & $\mathrm{SI}^{\mathrm{e}}$ & \\
\hline $3 a$ & $>50$ & $98 \pm 1$ & $91 \pm 2$ & $15.6 \pm 1.1$ & $>3.2$ & $17 \pm 8$ \\
\hline $3 b$ & $>100$ & $90 \pm 3$ & $79 \pm 3$ & $3.9 \pm 1.1$ & $>25.6$ & $\mathrm{NI}$ \\
\hline $3 c$ & $>200$ & $88 \pm 10$ & $83 \pm 6$ & $8.1 \pm 3.0$ & $>24.7$ & $8 \pm 5$ \\
\hline $3 d$ & $>50$ & $23 \pm 13$ & $33 \pm 2$ & ND & ND & $7 \pm 4$ \\
\hline $3 e$ & $>50$ & $95 \pm 2$ & $64 \pm 2$ & ND & ND & $8 \pm 3$ \\
\hline $3 \mathrm{f}$ & $<50$ & $92 \pm 5$ & $81 \pm 4$ & ND & ND & $9 \pm 2$ \\
\hline $3 g$ & $<50$ & $78 \pm 11$ & $90 \pm 2$ & ND & ND & $7 \pm 4$ \\
\hline $3 h$ & $>50$ & $74 \pm 14$ & $83 \pm 2$ & $3.9 \pm 1.7$ & $>12.8$ & $11 \pm 9$ \\
\hline $3 \mathrm{i}$ & $<50$ & $96 \pm 3$ & $72 \pm 5$ & ND & ND & $\mathrm{NI}$ \\
\hline $3 \mathrm{j}$ & $>100$ & $72 \pm 15$ & $69 \pm 2$ & ND & ND & $\mathrm{NI}$ \\
\hline $3 k$ & $<50$ & $95 \pm 2$ & $66 \pm 3$ & ND & ND & $\mathrm{NI}$ \\
\hline 31 & $>50$ & $96 \pm 2$ & $65 \pm 2$ & ND & ND & $\mathrm{NI}$ \\
\hline $3 \mathrm{~m}$ & $>200$ & $82 \pm 4$ & $77 \pm 5$ & $11.8 \pm 0.5$ & $>16.9$ & $\mathrm{NI}$ \\
\hline $3 n$ & $<50$ & $95 \pm 2$ & $65 \pm 1$ & ND & ND & $\mathrm{NI}$ \\
\hline 30 & $<50$ & $99 \pm 1$ & $87 \pm 3$ & ND & ND & $18 \pm 4$ \\
\hline $3 p$ & $<50$ & $99 \pm 1$ & $86 \pm 3$ & ND & ND & $12 \pm 6$ \\
\hline $3 r$ & $>200$ & $70 \pm 10$ & $79 \pm 3$ & $16.5 \pm 4.2$ & $>6.1$ & $\mathrm{NI}$ \\
\hline $3 s$ & $>100$ & $58 \pm 11$ & $65 \pm 13$ & ND & ND & $\mathrm{NI}$ \\
\hline $3 t$ & $<50$ & $99 \pm 1$ & $92 \pm 2$ & ND & ND & $14 \pm 2$ \\
\hline
\end{tabular}

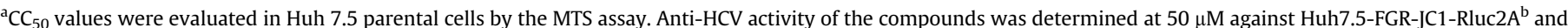

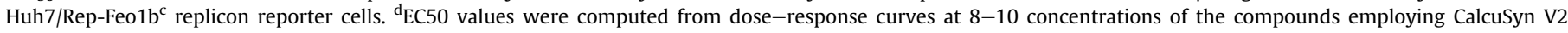

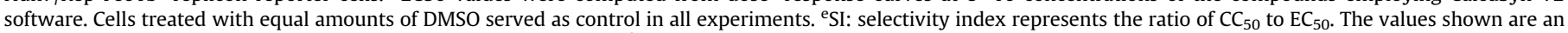

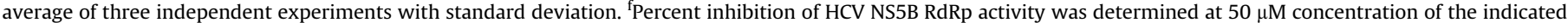

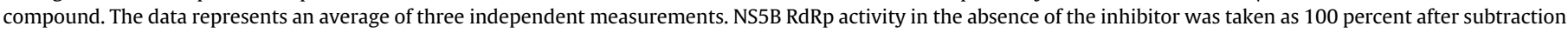
of residual background activity. NI, no inhibition; ND, not determined. 
(Fig. 3). Compound $\mathbf{3 b}$ was bioactive in all six of the cancer cell lines with $\mathrm{IC}_{50}$ values in micromolar ranges (Table 2 ). In this study, diflunisal was included as an experimental control.

Compound $\mathbf{3 b}$, bearing 2-pyridinyl group in the hydrazone core inhibited cell proliferation with $\mathrm{IC}_{50}$ values between 4.74 and $16.21 \mu \mathrm{M}$ as shown in Table 2. While Diflunisal showed no inhibition against Huh7, HepG2, Hep3B, and SNU-475 liver cells, compound $\mathbf{3 b}$ by contrast demonstrated anticancer activity against the same cells with $\mathrm{IC}_{50}$ values $10.0,10.34,16.21$ and $8.33 \mu \mathrm{M}$, respectively. Compound $\mathbf{3 b}$ exhibited the highest growth inhibitory activity against Mahlavu lines $\left(\mathrm{IC}_{50}=4.74 \mu \mathrm{M}\right)$.

2.2.2.1. Effect of diflunisal and compound $\mathbf{3 b}$ on the morphology of Huh 7 and Mahlavu cells. It is known that a cell that is undergoing apoptosis exhibits nuclear condensation and DNA fragmentation, which can be detected by staining with Hoechst 33258 and fluorescence microscopy. To examine the nature of cell death induced upon compound treatment, we next analyzed the changes in cell morphology with light microscopy. Towards this end, human liver cancer cells were treated with diflunisal and compound $\mathbf{3 b}$ at their $\mathrm{IC}_{50}$ values for $72 \mathrm{~h}$ (Table 2 ) and compared against DMSO treated controls. As shown in Fig. 4, compound $\mathbf{3 b}$ induced cell death with diverse morphologies. In Huh7 cells, treatment with $\mathbf{3 b}$ at $\mathrm{IC}_{50}$ concentration, resulted in nuclear condensation and DNA fragmentation in the cells, which was in parallel with their cell cycle analysis but no such morphological change were observed upon diflunisal (Fig. 4).

2.2.2.2. Effect of diflunisal and compound $\mathbf{3 b}$ on cell cycle arrest in Huh 7 and Mahlavu cells. In order to investigate the effects of the compounds on cell cycle, we treated the liver cancer cells with

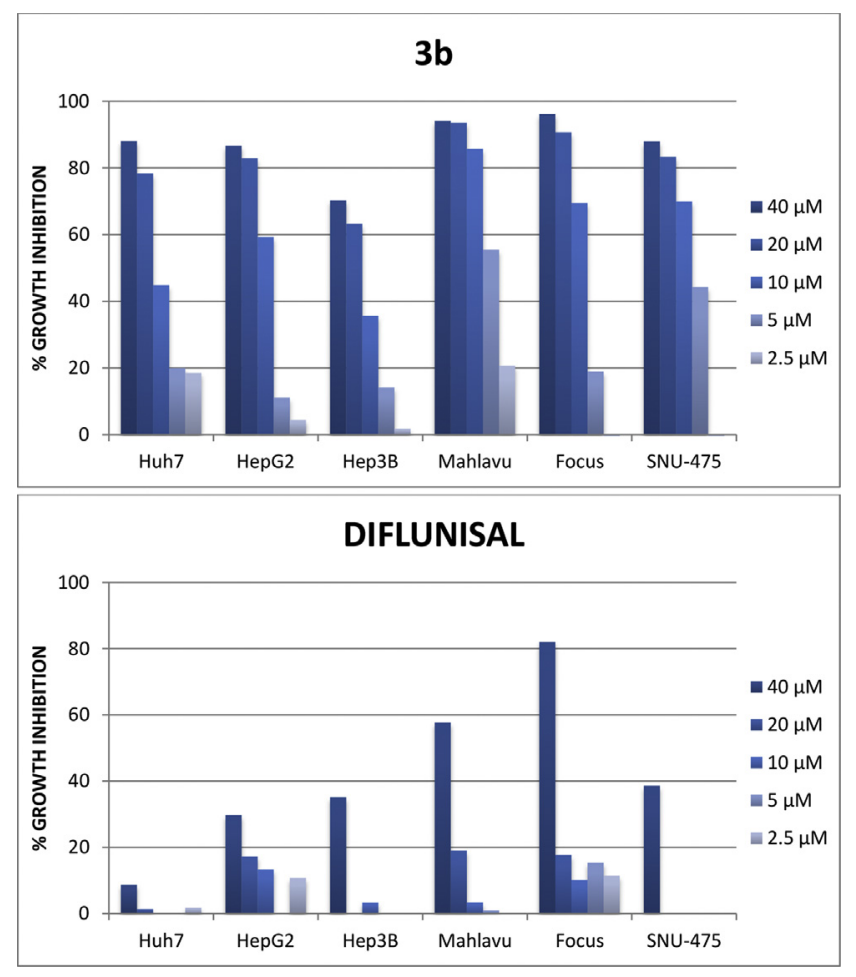

Fig. 3. Cytotoxicity induced by the compounds on liver cancer cell lines (Huh7, HepG2, Hep3B, Mahlavu, FOCUS and SNU-475). The cells were treated with increased concentration of the compound $(2.5-40 \mu \mathrm{M})$ for $72 \mathrm{~h}$. NCI-60 SRB assay was then performed. Absorbance values were obtained and normalized to DMSO control. The experiment was conducted in triplicate.
Table 2

$\mathrm{IC}_{50}$ values of $\mathbf{3 b}$ on liver cancer cell lines.

\begin{tabular}{lll}
\hline Cell line & Diflunisal & $3 \mathrm{~b}$ \\
\cline { 2 - 2 } & $\mathrm{IC}_{50}(\mu \mathrm{M})$ & $\mathrm{IC}_{50}(\mu \mathrm{M})$ \\
\hline Huh7 & No inhibition & 10 \\
HepG2 & No inhibition & 10.34 \\
Hep3B & No inhibition & 16.21 \\
Mahlavu & 51.7 & 4.74 \\
Focus & 29.8 & 9.29 \\
SNU-475 & No inhibition & 8.33 \\
\hline
\end{tabular}

DMSO or compounds at their $\mathrm{IC}_{50}$ concentrations for $72 \mathrm{~h}$ and stained the cells with propidium iodide. This assay revealed that compound 3b induced SubG1/Go arrest in Mahlavu cells lines, with the effect being more prounced in Mahlavu cells (Fig. 5).

2.2.2.3. Apoptosis induction by compound $\mathbf{3 b}$. The changes observed in fluorescent microscopy together with SubG1 cell cycle arrest suggested that the compound induced apoptotic cell cycle arrest. In order to confirm this, the presence of cleaved PARP (an indicator of apoptitic induction) was investigated in cells treated with DMSO control, diflunisal or $\mathbf{3 b}$ according to $\mathrm{IC}_{50}$ concentrations for 72 h. In Huh7 cells, no cleavage could be observed. On the other hand, compound $\mathbf{3 b}$ caused cleavage of PARP protein indicating that 3b induced apoptosis in Mahlavu liver cancer cell line (Fig. 6).

\section{Conclusion}

In this study, a series of $2^{\prime}, 4^{\prime}$-difluoro-4-hydroxy- $N$-(arylmethylidene)biphenyl-3-carbohydrazide [3a-t] have been synthesized and evaluated for their anti-HCV and anticancer activity. The results revealed increase in cleaved PARP (a marker for apoptosis) in Mahlavu cells treated with $\mathbf{3 b}$ indicating induction of apoptosis. In Huh7 cells no cleaved fragment was observed. According to FACS analysis, in both cell lines, treatment with compound $\mathbf{3 b}$ resulted in SubG1 cell cycle arrest. Together, this data indicates that compound 3b may be a promising lead candidate for further optimization and development as a prospective anti-HCV and hepatocellular carcinoma inhibitory agent.

\section{Experimental section}

\subsection{Chemistry}

All reagents and solvents were obtained from commercial suppliers and were used without further purification. Merck silica gel 60 F254 plates were used for analytical TLC. Melting points wee determined using Schmelzpunktbestimmer SMP II apparatus and were incorrect. ${ }^{1} \mathrm{H}$ and ${ }^{13} \mathrm{C}$ NMR spectra were recorded on $300 \mathrm{MHz}$ or $500 \mathrm{MHz}$ Varian UNITY INOVA or HD BRUKER $300 \mathrm{MHz}$ Ultrashield TM spectrometer. Elemental analyses were determined by CHNS-932 (LECO). FT-IR spectra were recorded on a Schimadzu FTIR-8400S spectrometer. HR-MS mass spectra were acquired using a Jeol JMS-700 spectrometer. Purity of the synthesized compounds has been demonstrated by HPLC analysis using reversed-phase chromatography. The liquid chromatographic system consists of an Agilent Technologies 1100 series instrument equipped with a quaternary solvent delivery system and a model Agilent series G1315 A photodiode array detector. A Rheodyne syringe loading sample injector with a $50-\mu \mathrm{L}$ sample loop was used for the injection of the analytes. Chromatographic data were collected and processed using Agilent Chemstation Plus software. The separation was performed at ambient temperature using a reverse phase ACE 


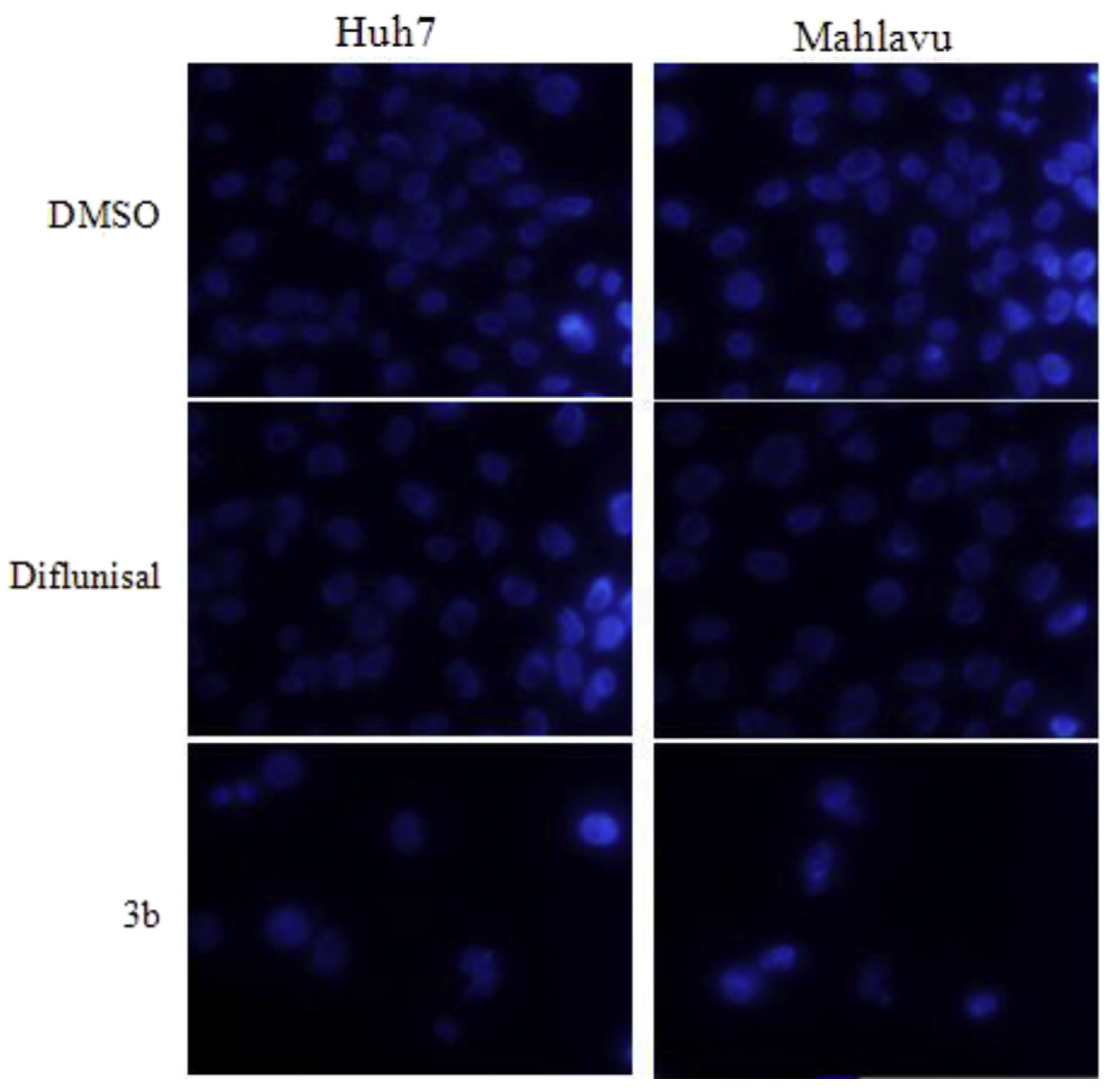

Fig. 4. Nuclear Hoechst (33258) staining $(40 \times)$ of liver cancer cells treated with $\mathrm{IC}_{50}$ concentrations of the compounds or DMSO control for 72 h.

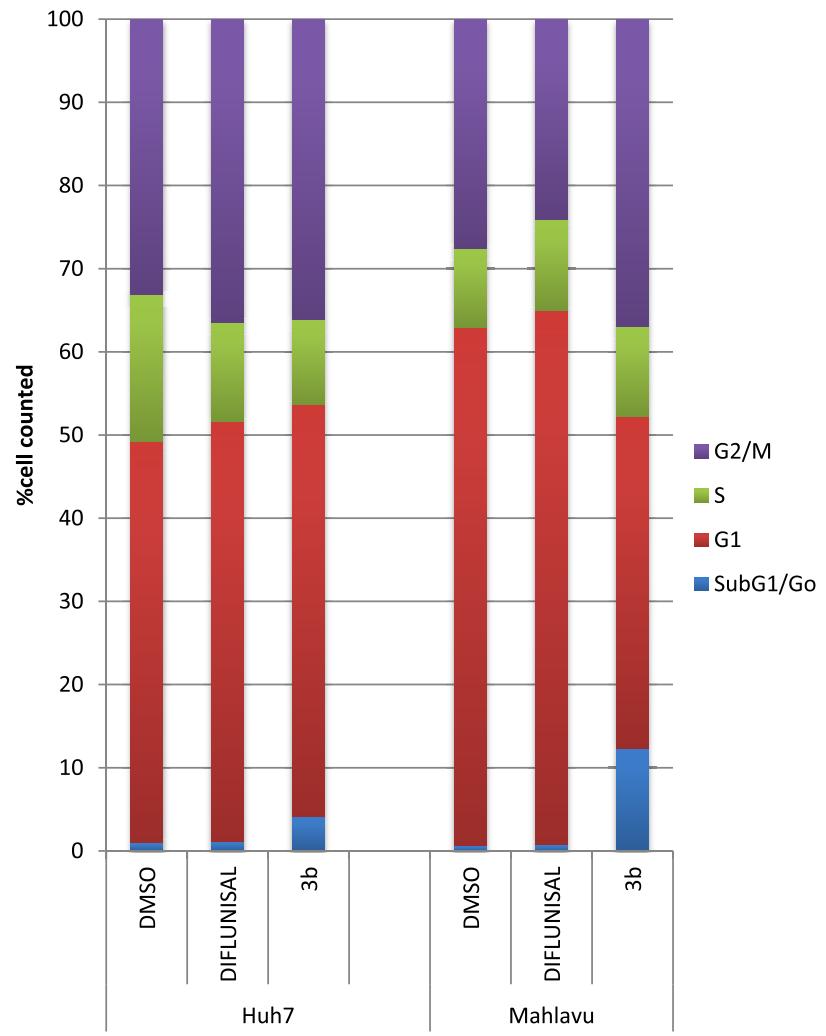

Fig. 5. Cell cycle distribution of liver cancer cells (Huh7 and Mahlavu) treated with $\mathrm{IC}_{50}$ concentrations of the compounds or DMSO control for $72 \mathrm{~h}$.
$\mathrm{C}_{18}(4.0 \times 100 \mathrm{~mm})$ column. All experiments were performed in gradient mode. $\mathrm{ACN} / \mathrm{H}_{2} \mathrm{O}$ system was used as gradient system: 50:50 from 0 to $3 \mathrm{~min} ; 75: 25$ to $50: 50$ from 3 to $6 \mathrm{~min}$; 100:0 to $75: 25$ from 6 to $12 \mathrm{~min}$; the flow rate was $1.0 \mathrm{~mL} / \mathrm{min}$ with monitoring at $254 \mathrm{~nm}$.

4.1.1. Methyl 2',4'-difluoro-4-hydroxybiphenyl-3-carboxylate (1)

This was prepared described in the literature [10].

4.1.2. 2',4'-difluoro-4-hydroxybiphenyl-3-carboxylic acid hydrazide (2)

This was prepared described in the literature [10].

4.1.3. General procedure for the synthesized of the compounds

A mixture of appropriate aldehydes and an equimolar amount of diflunisal hydrazide in ethanol was refluxed for $2 \mathrm{~h}$ and novel $2^{\prime}, 4^{\prime}-$
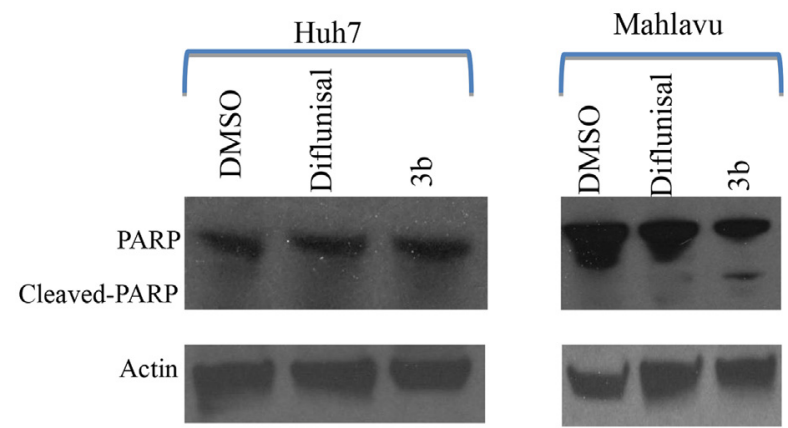

Fig. 6. Western blot results of liver cancer cells treated with $\mathrm{IC}_{50}$ concentrations of the compounds or DMSO control for $72 \mathrm{~h}$. 
difluoro-4-hydroxy- $N^{\prime}$ (arylmethylidene)biphenyl-3-carbohydra zide [3a-t] were obtained.

4.1.3.1. 2',4'-Difluoro-4-hydroxy-N'-[(thiophen-2-yl)methylidene] biphenyl-3-carbohydrazide (3a). Dark brown solid; Yield: 90\%; HPLC: $\mathrm{t}_{\mathrm{R}}$ (min.): 8.94; Mp $251{ }^{\circ} \mathrm{C}$; FTIR $\left(\mathrm{cm}^{-1}\right): 3242(\mathrm{O}-\mathrm{H} \& \mathrm{~N}-\mathrm{H})$, 3072, 3032 (=C-H arom.), $1637(\mathrm{C}=\mathrm{O}), 1608(\mathrm{C}=\mathrm{N}) ;{ }^{1} \mathrm{H}$ NMR (300 MHz), (DMSO-d $/ 6$ TMS) $\delta$ ppm: $7.08\left(\mathrm{~d}, 1 \mathrm{H}, J=8.4 \mathrm{~Hz}, \mathrm{H}_{5}\right), 7.22$ (t, 1H, H11), $7.37\left(\mathrm{t}, 1 \mathrm{H}, \mathrm{H}_{9}\right), 7.49-7.65(\mathrm{~m}, 4 \mathrm{H}, \mathrm{Ar}-\mathrm{H}), 7.72(\mathrm{~d}, 1 \mathrm{H}$, $\left.\mathrm{J}=5.1 \mathrm{~Hz}, \mathrm{H}_{14}\right), 7.99\left(\mathrm{~s}, 1 \mathrm{H}, \mathrm{H}_{2}\right), 8.67(\mathrm{~s}, 1 \mathrm{H}, \mathrm{CH}=\mathrm{N}), 11.90(\mathrm{~s}, 2 \mathrm{H}$, $\mathrm{Ar}-\mathrm{OH} \& \mathrm{CO}-\mathrm{NH}-\mathrm{N}=\mathrm{CH}$ ); Anal. Calcd for $\mathrm{C}_{18} \mathrm{H}_{12} \mathrm{~F}_{2} \mathrm{~N}_{2} \mathrm{O}_{2} \mathrm{~S}$ : C, 60.33; H, 3.38; N, 7.82; S, 8.95; found C, 59.82; H, 3.36; N, 7.79; S, 9.42.

4.1.3.2. 2',4'-Difluoro-4-hydroxy-N'-[(pyridin-2-yl)methylidene] biphenyl-3-carbohydrazide (3b). Light yellow solid; Yield: 80\%; HPLC: $\mathrm{t}_{\mathrm{R}}$ (min.): 2.76; Mp $241{ }^{\circ} \mathrm{C}$; FTIR $\left(\mathrm{cm}^{-1}\right)$ : $3254(\mathrm{O}-\mathrm{H} \& \mathrm{~N}-\mathrm{H})$, 3076, 3045 (=C-H arom.), $1639(\mathrm{C}=\mathrm{O}), 1614(\mathrm{C}=\mathrm{N}) ;{ }^{1} \mathrm{H}$ NMR (300 MHz), (DMSO- $\left.d_{6} / \mathrm{TMS}\right) \delta$ ppm: $7.10\left(\mathrm{~d}, 1 \mathrm{H}, J=8.5 \mathrm{~Hz}, \mathrm{H}_{5}\right) ; 7.22$ $\left(\mathrm{t}, 1 \mathrm{H}, \mathrm{H}_{11}\right) ; 7.35-8.65(\mathrm{~m}, 8 \mathrm{H}, \mathrm{Ar}-\mathrm{H}) ; 8.48(\mathrm{~s}, 1 \mathrm{H}, \mathrm{CH}=\mathrm{N}) ; 11.85(\mathrm{~s}$, $1 \mathrm{H}, \quad \mathrm{Ar}-\mathrm{OH}) ; 12.07(\mathrm{~s}, 1 \mathrm{H}, \mathrm{CO}-\mathrm{NH}-\mathrm{N}=\mathrm{CH})$; Anal. Calcd for $\mathrm{C}_{19} \mathrm{H}_{13} \mathrm{~F}_{2} \mathrm{~N}_{3} \mathrm{O}_{2}$ : C, 64.59; $\mathrm{H}, 3.71 ; \mathrm{N}, 11.89$; found $\mathrm{C}, 64.32 ; \mathrm{H}, 3.78 ; \mathrm{N}$, 11.80 .

4.1.3.3. 2',4'-Difluoro-4-hydroxy- $N^{\prime}-[($ pyridin-3-yl)methylidene] biphenyl-3-carbohydrazide (3c). Off-white solid; Yield: 88\%; HPLC: $\mathrm{t}_{\mathrm{R}}$ (min.): 2.39; Mp 277-278 ${ }^{\circ} \mathrm{C}$; FTIR $\left(\mathrm{cm}^{-1}\right)$ : $3242(\mathrm{O}-\mathrm{H} \& \mathrm{~N}-\mathrm{H})$, 3041, 3032 (=C-H arom.), $1629(\mathrm{C}=\mathrm{O}), 1608(\mathrm{C}=\mathrm{N})$; ${ }^{1} \mathrm{H}$ NMR (300 MHz), (DMSO- $\left.d_{6} / \mathrm{TMS}\right) \delta \mathrm{ppm}: 7.06\left(\mathrm{~d}, 1 \mathrm{H}, J=8.7 \mathrm{~Hz}, \mathrm{H}_{5}\right) ; 7.22$ $\left(\mathrm{t}, 1 \mathrm{H}, \mathrm{H}_{11}\right) ; 7.39\left(\mathrm{t}, 1 \mathrm{H}, \mathrm{H}_{9}\right) ; 7.43-8.65(\mathrm{~m}, 6 \mathrm{H}, \mathrm{Ar}-\mathrm{H}) ; 8.02(\mathrm{~s}, 1 \mathrm{H}$, $\left.\mathrm{H}_{2}\right) ; 8.88(\mathrm{~s}, 1 \mathrm{H}, \mathrm{CH}=\mathrm{N}) ; 11.92(\mathrm{~s}, 1 \mathrm{H}, \mathrm{Ar}-\mathrm{OH}) ; 12.05(\mathrm{~s}, 1 \mathrm{H}$, $\mathrm{CO}-\mathrm{NH}-\mathrm{N}=\mathrm{CH}$ ); Anal. Calcd for $\mathrm{C}_{19} \mathrm{H}_{13} \mathrm{~F}_{2} \mathrm{~N}_{3} \mathrm{O}_{2}: \mathrm{C}, 64.59 ; \mathrm{H}, 3.71 ; \mathrm{N}$, 11.89; found C, 63.75; $\mathrm{H}, 3.76 ; \mathrm{N}, 11.74$.

4.1.3.4. 2',4'-Difluoro-4-hydroxy- $N^{\prime}-[($ pyridin-4-yl)methylidene] biphenyl-3-carbohydrazide (3d). Off-white solid; Yield: 86\%; HPLC: $\mathrm{t}_{\mathrm{R}}$ (min.): 2.51; Mp 261-263 ${ }^{\circ} \mathrm{C}$; FTIR $\left(\mathrm{cm}^{-1}\right)$ : $3251(\mathrm{O}-\mathrm{H} \& \mathrm{~N}-\mathrm{H})$, $3036(=\mathrm{C}-\mathrm{H}$ arom. $), 1646(\mathrm{C}=\mathrm{O}), 1608(\mathrm{C}=\mathrm{N}) ;{ }^{1} \mathrm{H}$ NMR $(300 \mathrm{MHz})$, (DMSO-d $\left.d_{6} / \mathrm{TMS}\right) \delta$ ppm: $7.11\left(\mathrm{~d}, 1 \mathrm{H}, J=8.7 \mathrm{~Hz}, \mathrm{H}_{5}\right) ; 7.22\left(\mathrm{t}, 1 \mathrm{H}, \mathrm{H}_{11}\right)$; $7.37\left(\mathrm{t}, 1 \mathrm{H}, \mathrm{H}_{9}\right) ; 7.59-7.71 \& 8.66-8.68(\mathrm{~m}, 6 \mathrm{H}, \mathrm{Ar}-\mathrm{H}) ; 8.02(\mathrm{~s}, 1 \mathrm{H}$, $\left.\mathrm{H}_{2}\right) ; 8.44(\mathrm{~s}, 1 \mathrm{H}, \mathrm{CH}=\mathrm{N}) ; 12.12(\mathrm{~s}, 2 \mathrm{H}, \mathrm{Ar}-\mathrm{OH} \& \mathrm{CO}-\mathrm{NH}-\mathrm{N}=\mathrm{CH})$; DART-MS; $\quad(\mathrm{m} / \mathrm{z}, \quad$ Calcd./Found $): \quad 354,1048 / 354,1047$ $\left[\mathrm{C}_{19} \mathrm{H}_{13} \mathrm{~F}_{2} \mathrm{~N}_{3} \mathrm{O}_{2}+\mathrm{H}\right]^{+} ; \quad 707.2024 / 707.2009 \quad\left[2\left(\mathrm{C}_{19} \mathrm{H}_{13} \mathrm{~F}_{2} \mathrm{~N}_{3} \mathrm{O}_{2}\right)+\mathrm{H}\right]^{+}$; Anal. Calcd for $\mathrm{C}_{19} \mathrm{H}_{13} \mathrm{~F}_{2} \mathrm{~N}_{3} \mathrm{O}_{2}$ : C, 64.59; $\mathrm{H}, 3.71 ; \mathrm{N}, 11.89$; found $\mathrm{C}$, 64.40; H, 4.06; N, 11.67 .

4.1.3.5. 2',4'-Difluoro-4-hydroxy-N'-[(5-methylthiophen-2-yl)methylidene Jbiphenyl-3-carbohydrazide (3e). Light brown solid; Yield: 95\%; HPLC: $t_{R}$ (min.): 9.03; Mp $242{ }^{\circ} \mathrm{C}$; FTIR $\left(\mathrm{cm}^{-1}\right): 3246$ $(\mathrm{O}-\mathrm{H} \& \mathrm{~N}-\mathrm{H}), 3076,3047$ (=C-H arom.), $1639(\mathrm{C}=\mathrm{O}), 1610(\mathrm{C}=\mathrm{N})$; ${ }^{1} \mathrm{H}$ NMR (300 MHz), $\left(\mathrm{CD}_{3} \mathrm{COCD}_{3}-d_{6} / \mathrm{TMS}\right) \delta \mathrm{ppm}: 2.52(\mathrm{~s}, 3 \mathrm{H}$, methyl); $6.87\left(\mathrm{~d}, 1 \mathrm{H}, J=3.6 \mathrm{~Hz}, \mathrm{H}_{4}\right.$, thiophene); $7.08(\mathrm{~d}, 1 \mathrm{H}$, $\left.J=8.7 \mathrm{~Hz}, \mathrm{H}_{5}\right) ; 7.22\left(\mathrm{t}, 1 \mathrm{H}, \mathrm{H}_{11}\right) ; 7.30\left(\mathrm{~d}, 1 \mathrm{H}, J=3.6 \mathrm{~Hz}, \mathrm{H}_{3}\right.$, thiophene); 7.38 (t, 1H, $\left.\mathrm{H}_{9}\right)$; 7.56-7.64 (m, 2H, Ar-H); $7.99\left(\mathrm{~s}, 1 \mathrm{H}, \mathrm{H}_{2}\right)$; $8.59(\mathrm{~s}, 1 \mathrm{H}, \mathrm{CH}=\mathrm{N}) ; 11.78(\mathrm{~s}, 1 \mathrm{H}, \mathrm{Ar}-\mathrm{OH}) ; 11.99(\mathrm{~s}, 1 \mathrm{H}, \mathrm{CO}-\mathrm{NH}-\mathrm{N}=$ $\mathrm{CH}) ;{ }^{13} \mathrm{C}$ NMR (150 MHz) (DMSO-d $6 /$ TMS) $\delta$ ppm: 15.86, 104.93,112.47, 116.79,118.02,124.54, 125.50, 126.90, 129.17, 132.16, 132.39, 134.45, 136.93, 143.95, $144.70(-\mathrm{N}=\mathrm{CH}), 158.66 \& 160.31$ (C-F), 159.11, 161.14\&162.77 (C-F), $164.59(-\mathrm{C}=\mathrm{O})$; Anal. Calcd for $\mathrm{C}_{19} \mathrm{H}_{14} \mathrm{~F}_{2} \mathrm{~N}_{2} \mathrm{O}_{2} \mathrm{~S}$ : C, 61.28; H, 3.79; N, 7.52; S, 8.61; found C, 60.78; $\mathrm{H}$, $3.66 ; \mathrm{N}, 7.33 ; \mathrm{S}, 9.45$.

4.1.3.6. 2',4'-Difluoro-4-hydroxy-N'-[(3-bromophenyl)methylidene] biphenyl-3-carbohydrazide (3f). White solid; Yield: $81 \%$; HPLC: $t_{R}$ (min.): 4.75; Mp $262{ }^{\circ} \mathrm{C}$; FTIR $\left(\mathrm{cm}^{-1}\right)$ : $3232(\mathrm{O}-\mathrm{H} \& \mathrm{~N}-\mathrm{H}), 3047$ (= $\mathrm{C}-\mathrm{H}$ arom.), $1606(\mathrm{C}=\mathrm{O}), 1606(\mathrm{C}=\mathrm{N}) ;{ }^{1} \mathrm{H}$ NMR $(300 \mathrm{MHz})$, (DMSO- $d_{6} /$ TMS $) \delta$ ppm: $7.09\left(\mathrm{~d}, 1 \mathrm{H}, J=8.4 \mathrm{~Hz}, \mathrm{H}_{5}\right) ; 7.21\left(\mathrm{t}, 1 \mathrm{H}, \mathrm{H}_{11}\right) ; 7.37(\mathrm{t}$, $\left.1 \mathrm{H}, \mathrm{H}_{9}\right) ; 7.42-7.95(\mathrm{~m}, 6 \mathrm{H}, \mathrm{Ar}-\mathrm{H}) ; 8.01\left(\mathrm{~s}, 1 \mathrm{H}, \mathrm{H}_{2}\right) ; 8.41(\mathrm{~s}, 1 \mathrm{H}, \mathrm{CH}=$ $\mathrm{N}) ; 11.94(2 \mathrm{~s}, 2 \mathrm{H}, \mathrm{CO}-\mathrm{NH}-\mathrm{N}=\mathrm{CH} \& \mathrm{Ar}-\mathrm{OH}) .{ }^{13} \mathrm{C} \mathrm{NMR}(150 \mathrm{MHz})$ (DMSO-d $6 /$ TMS) $\delta$ ppm: 104.92, 112.49, 117.04, 118.08, 122.64, 124.50, 125.61, 126.85, 129.54, 129.77, 131.53, 132.15, 133.30, 134.57, 136.98, $\quad 147.49 \quad(-\mathrm{N}=\mathrm{CH}), \quad 158.65 \& 160.29 \quad(\mathrm{C}-\mathrm{F}) ; \quad 158.80$, 161.13\&162.77 (C-F); $164.79 \quad(-\mathrm{C}=0)$; Anal. Calcd for $\mathrm{C}_{20} \mathrm{H}_{13} \mathrm{BrF}_{2} \mathrm{~N}_{2} \mathrm{O}_{2}$ : C, 55.70; H, 3.04; N, 6.50; found C, 55.34; $\mathrm{H}, 2.93$; $\mathrm{N}, 6.47$.

4.1.3.7. 2',4'-Difluoro-4-hydroxy- $N^{\prime}-[(2-$ chlorophenyl)methylidene] biphenyl-3-carbohydrazide (3g). Light yellow solid; Yield: 86\%; HPLC: $t_{R}$ (min.): 9.65; Mp 269-270 ${ }^{\circ} \mathrm{C}$; FTIR $\left(\mathrm{cm}^{-1}\right): 3261$ $(\mathrm{O}-\mathrm{H} \& \mathrm{~N}-\mathrm{H}), 3078$ (=C-H arom.), $1639(\mathrm{C}=\mathrm{O}), 1614(\mathrm{C}=\mathrm{N}) ;{ }^{1} \mathrm{H}$ NMR (300 MHz), (DMSO- $d_{6} /$ TMS $) \delta$ ppm: $7.06\left(\mathrm{~d}, 1 \mathrm{H}, J=8.4 \mathrm{~Hz}, \mathrm{H}_{5}\right)$; $7.22\left(\mathrm{t}, 1 \mathrm{H}, \mathrm{H}_{11}\right) ; 7.39\left(\mathrm{t}, 1 \mathrm{H}, \mathrm{H}_{9}\right) ; 7.33-7.70(\mathrm{~m}, 5 \mathrm{H}, \mathrm{Ar}-\mathrm{H}) ; 8.02(\mathrm{~s}$, $\left.1 \mathrm{H}, \quad \mathrm{H}_{2}\right) ; 8.84(\mathrm{~s}, 1 \mathrm{H}, \mathrm{CH}=\mathrm{N}) ; 12.28(\mathrm{~s}, 2 \mathrm{H}, \quad \mathrm{CO}-\mathrm{NH}-\mathrm{N}=$ CH\&Ar-OH). ${ }^{13} \mathrm{C}$ NMR (75 MHz) (DMSO-d 6 /TMS) $\delta$ ppm: 104.90 , $112.57,116.73,118.28,124.60,124.77,125.05,127.49,128.13,129.27$, $130.43, \quad 131.88, \quad 132.17, \quad 133.80, \quad 134.60, \quad 144.91 \quad(-\mathrm{N}=\mathrm{CH})$, $157.91 \& 160.33(\mathrm{C}-\mathrm{F}), 159.98,161.20 \& 163.44(\mathrm{C}-\mathrm{F}), 165.38(-\mathrm{C}=\mathrm{O})$; Anal. Calcd for $\mathrm{C}_{20} \mathrm{H}_{13} \mathrm{ClF}_{2} \mathrm{~N}_{2} \mathrm{O}_{2}$ : C, 62.11; $\mathrm{H}, 3.39 ; \mathrm{N}, 7.24$; found $\mathrm{C}$, 61.39; H, 3.23; N, 7.08 .

4.1.3.8. 2',4'-Difluoro-4-hydroxy-N'-[(2-chloro-6-fluorophenyl)methylidene Jbiphenyl-3-carbohydrazide (3h). Light yellow solid; Yield: 78\%; HPLC: $t_{R}$ (min.): 9.38; Mp $260{ }^{\circ} \mathrm{C}$; FTIR $\left(\mathrm{cm}^{-1}\right): 3227$ (O-H\&N-H), 3080, 3051 (=C-H arom.), $1647(\mathrm{C}=\mathrm{O}), 1602(\mathrm{C}=\mathrm{N})$; ${ }^{1} \mathrm{H}$ NMR (300 MHz), (DMSO- $\left.d_{6} / \mathrm{TMS}\right) \delta \mathrm{ppm}: 7.09(\mathrm{~d}, 1 \mathrm{H}, J=8.4 \mathrm{~Hz}$, $\left.\mathrm{H}_{5}\right) ; 7.22\left(\mathrm{t}, 1 \mathrm{H}, \mathrm{H}_{11}\right) ; 7.33-7.70(\mathrm{~m}, 6 \mathrm{H}, \mathrm{Ar}-\mathrm{H}) ; 8.01\left(\mathrm{~s}, 1 \mathrm{H}, \mathrm{H}_{2}\right) ; 8.69$ $(\mathrm{s}, 1 \mathrm{H}, \mathrm{CH}=\mathrm{N}) ; 11.92(\mathrm{~s}, 1 \mathrm{H}, \mathrm{Ar}-\mathrm{OH}) ; 12.11(\mathrm{~s}, 1 \mathrm{H}, \mathrm{CO}-\mathrm{NH}-\mathrm{N}=\mathrm{CH})$; Anal. Calcd for $\mathrm{C}_{20} \mathrm{H}_{12} \mathrm{ClF}_{3} \mathrm{~N}_{2} \mathrm{O}_{2}$ : C, 59.35; $\mathrm{H}, 2.99 ; \mathrm{N}, 6.92$; found $\mathrm{C}$, 58.74; H, 2.92; N, 6.75 .

4.1.3.9. 2',4'-Difluoro-4-hydroxy- $N^{\prime}-[(2,6$-dichlorophenyl)methylidene biphenyl-3-carbohydrazide (3i). Dark yellow solid; Yield: 95\%; HPLC: $t_{R}$ (min.): 9.76; Mp $208{ }^{\circ} \mathrm{C} ;$ FTIR $\left(\mathrm{cm}^{-1}\right): 3244$ $(\mathrm{O}-\mathrm{H} \& \mathrm{~N}-\mathrm{H}), 3074,3032$ ( $=\mathrm{C}-\mathrm{H}$ arom.), $1637(\mathrm{C}=\mathrm{O}), 1608(\mathrm{C}=\mathrm{N})$; ${ }^{1} \mathrm{H}$ NMR (300 MHz), (DMSO- $\left.d_{6} / \mathrm{TMS}\right) \delta \mathrm{ppm}: 7.10(\mathrm{~d}, 1 \mathrm{H}, J=8.7 \mathrm{~Hz}$, $\left.\mathrm{H}_{5}\right) ; 7.22\left(\mathrm{t}, 1 \mathrm{H}, \mathrm{H}_{11}\right) ; 7.36\left(\mathrm{t}, 1 \mathrm{H}, \mathrm{H}_{9}\right) ; 7.42-7.67(\mathrm{~m}, 5 \mathrm{H}, \mathrm{Ar}-\mathrm{H}) ; 8.02$ $\left(\mathrm{s}, 1 \mathrm{H}, \mathrm{H}_{2}\right) ; 8.66(\mathrm{~s}, 1 \mathrm{H}, \mathrm{CH}=\mathrm{N}) ; 11.87(\mathrm{~s}, 1 \mathrm{H}, \mathrm{Ar}-\mathrm{OH}) ; 12.16(\mathrm{~s}, 1 \mathrm{H}$, $\mathrm{CO}-\mathrm{NH}-\mathrm{N}=\mathrm{CH}$ ); Anal. Calcd for $\mathrm{C}_{20} \mathrm{H}_{12} \mathrm{Cl}_{2} \mathrm{~F}_{2} \mathrm{~N}_{2} \mathrm{O}_{2}$ : C, 57.03; $\mathrm{H}$, 2.87; N, 6.65; found C, 56.92; H, 2.79; N, 6.62.

4.1.3.10. 2',4'-Difluoro-4-hydroxy-N'-[(2,6-difluorophenyl)methylidene Jbiphenyl-3-carbohydrazide (3j). Off-white solid; Yield: $90 \%$; HPLC: $\mathrm{t}_{\mathrm{R}}$ (min.): 8.89; $\mathrm{Mp} 280{ }^{\circ} \mathrm{C}$; FTIR $\left(\mathrm{cm}^{-1}\right): 3232(\mathrm{O}-\mathrm{H} \& \mathrm{~N}-\mathrm{H})$, 3046, 3022 (=C-H arom.), $1647(\mathrm{C}=\mathrm{O}), 1608(\mathrm{C}=\mathrm{N}) ;{ }^{1} \mathrm{H}$ NMR (300 MHz), (DMSO-d $/$ TMS) $\delta$ ppm: $7.09\left(\mathrm{~d}, 1 \mathrm{H}, J=8.7 \mathrm{~Hz}, \mathrm{H}_{5}\right)$; 7.23-7.66 (m, 7H, Ar-H); $8.01\left(\mathrm{~s}, 1 \mathrm{H}, \mathrm{H}_{2}\right) ; 8.61(\mathrm{~s}, 1 \mathrm{H}, \mathrm{CH}=\mathrm{N}) ; 12.16$ (s, $2 \mathrm{H}, \mathrm{Ar}-\mathrm{OH} \& \mathrm{CO}-\mathrm{NH}-\mathrm{N}=\mathrm{CH})$. HRMS $(\mathrm{EI}, \mathrm{m} / \mathrm{z})$ : monoisotopic mass for $\mathrm{C}_{20} \mathrm{H}_{12} \mathrm{~F}_{4} \mathrm{~N}_{2} \mathrm{O}_{2}$ (Calcd./Found): 388.0834/388.0842; Anal. Calcd for $\mathrm{C}_{20} \mathrm{H}_{12} \mathrm{~F}_{4} \mathrm{~N}_{2} \mathrm{O}_{2}$ : C, 61.86; $\mathrm{H}, 3.11 ; \mathrm{N}, 7.07$; found $\mathrm{C}, 61.16 ; \mathrm{H}$, $2.98 ; \mathrm{N}, 7.07$.

4.1.3.11. 2',4'-Difluoro-4-hydroxy-N'-[(3,4-dichlorophenyl)methylidene]biphenyl-3-carbohydrazide (3k). Off-white solid; Yield: $82 \%$; HPLC: $t_{R}$ (min.): 9.53; Mp 258-260 ${ }^{\circ} \mathrm{C}$; FTIR $\left(\mathrm{cm}^{-1}\right): 3255$ $(\mathrm{O}-\mathrm{H} \& \mathrm{~N}-\mathrm{H}), 3076,3037$ (=C $-\mathrm{H}$ arom.), $1639(\mathrm{C}=\mathrm{O}), 1614(\mathrm{C}=\mathrm{N})$; ${ }^{1} \mathrm{H}$ NMR (300 MHz), (DMSO- $\left.d_{6} / \mathrm{TMS}\right) \delta \mathrm{ppm}: 7.10$ (d, $1 \mathrm{H}, J=8.7 \mathrm{~Hz}$, $\left.\mathrm{H}_{5}\right) ; 7.21\left(\mathrm{t}, 1 \mathrm{H}, \mathrm{H}_{11}\right) ; 7.38\left(\mathrm{t}, 1 \mathrm{H}, \mathrm{H}_{9}\right) ; 7.57-8.01(\mathrm{~m}, 4 \mathrm{H}, \mathrm{Ar}-\mathrm{H}) ; 7.75$ $\left(\mathrm{s}, 1 \mathrm{H}, \mathrm{H}_{14}\right) ; 7.78\left(\mathrm{~s}, 1 \mathrm{H}, \mathrm{H}_{2}\right) ; 8.43(\mathrm{~s}, 1 \mathrm{H}, \mathrm{CH}=\mathrm{N}) ; 11.96(\mathrm{~s}, 1 \mathrm{H}$, $\mathrm{Ar}-\mathrm{OH}) ; 12.03(\mathrm{~s}, \quad 1 \mathrm{H}, \quad \mathrm{CO}-\mathrm{NH}-\mathrm{N}=\mathrm{CH})$; Anal. Calcd for $\mathrm{C}_{20} \mathrm{H}_{12} \mathrm{Cl}_{2} \mathrm{~F}_{2} \mathrm{~N}_{2} \mathrm{O}_{2}$ : C, 57.03; $\mathrm{H}, 2.87 ; \mathrm{N}, 6.65$; found $\mathrm{C}, 56.66 ; \mathrm{H}, 3.00$; $\mathrm{N}, 6.63$. 
4.1.3.12. 2',4'-Difluoro-4-hydroxy- $N^{\prime}-[(5-e t h y l t h i o p h e n-2-y l) m e t h y l-$ idene]biphenyl-3-carbohydrazide (3l). Dark brown solid; Yield: 93\%; HPLC: $t_{R}$ (min.): 9.28; $\operatorname{Mp~} 196{ }^{\circ} \mathrm{C}$; FTIR $\left(\mathrm{cm}^{-1}\right): 3228,3213$ $(\mathrm{O}-\mathrm{H} \& \mathrm{~N}-\mathrm{H}), 3074\left(=\mathrm{C}-\mathrm{H}\right.$ arom.), $1635(\mathrm{C}=\mathrm{O}), 1606(\mathrm{C}=\mathrm{N}) ;{ }^{1} \mathrm{H}$ NMR (300 MHz), (DMSO- $d_{6} /$ TMS) $\delta$ ppm: 1.25 (t, 3H, methyl); 2.83 (q, 2H, ethyl); 6.89-7.65 (m, 7H, Ar-H); $8.00\left(\mathrm{~s}, 1 \mathrm{H}, \mathrm{H}_{2}\right) ; 8.58(\mathrm{~s}, 1 \mathrm{H}$, $\mathrm{CH}=\mathrm{N}) ; 11.79(\mathrm{~s}, 1 \mathrm{H}, \mathrm{Ar}-\mathrm{OH}) ; 12.11(\mathrm{~s}, 1 \mathrm{H}, \mathrm{CO}-\mathrm{NH}-\mathrm{N}=\mathrm{CH})$; Anal. Calcd for $\mathrm{C}_{20} \mathrm{H}_{16} \mathrm{~F}_{2} \mathrm{~N}_{2} \mathrm{O}_{2} \mathrm{~S}$ : C, 62.16; $\mathrm{H}, 4.17 ; \mathrm{N}, 7.25 ; \mathrm{S}$ : 8.30; found $\mathrm{C}$, 61.95; H, 4.27; N, 6.90; S, 9.18.

4.1.3.13. 2',4'-Difluoro-4-hydroxy- $N^{\prime}$-[(4-cyanophenyl)methylidene] biphenyl-3-carbohydrazide (3m). Light yellow solid; Yield: $82 \%$; HPLC: $t_{R}$ (min.): 8.23; Mp 284-285 ${ }^{\circ} \mathrm{C} ;$ FTIR $\left(\mathrm{cm}^{-1}\right): 3227$ $(\mathrm{O}-\mathrm{H} \& \mathrm{~N}-\mathrm{H}), 3066,3022$ (=C-H arom.), $1633(\mathrm{C}=\mathrm{O}), 1612(\mathrm{C}=\mathrm{N})$; ${ }^{1} \mathrm{H}$ NMR (300 MHz), (DMSO-d $\left.d_{6} / \mathrm{TMS}\right) \delta \mathrm{ppm}: 7.11(\mathrm{~d}, 1 \mathrm{H}, J=8.4 \mathrm{~Hz}$, $\left.\mathrm{H}_{5}\right) ; 7.22\left(\mathrm{t}, 1 \mathrm{H}, \mathrm{H}_{11}\right) ; 7.39\left(\mathrm{t}, 1 \mathrm{H}, \mathrm{H}_{9}\right) ; 7.57-7.94(\mathrm{~m}, 6 \mathrm{H}, \mathrm{Ar}-\mathrm{H}) ; 8.01$ $\left(\mathrm{s}, 1 \mathrm{H}, \mathrm{H}_{2}\right) ; 8.52(\mathrm{~s}, 1 \mathrm{H}, \mathrm{CH}=\mathrm{N}) ; 12.06(\mathrm{~s}, 2 \mathrm{H}, \mathrm{CO}-\mathrm{NH}-\mathrm{N}=$ $\mathrm{CH} \& \mathrm{Ar}-\mathrm{OH}) .{ }^{13} \mathrm{C}$ NMR $(75 \mathrm{MHz}$ ) (DMSO-d $6 /$ TMS) $\delta$ ppm: 104.95 , 112.62, 117.16, 118.01, 119.10, 124.44 (CN), 124.62, 125.64, 128.25, $129.65, \quad 132.10, \quad 133.63, \quad 134.63, \quad 139.02, \quad 147.20 \quad(-\mathrm{N}=\mathrm{CH})$; $157.93 \& 160.26$ (C-F); 159.74, 161.21\&163.94 (C-10); 164.80 (-C= O); Anal. Calcd for $\mathrm{C}_{21} \mathrm{H}_{13} \mathrm{~F}_{2} \mathrm{~N}_{3} \mathrm{O}_{2}: \mathrm{C}, 66.84 ; \mathrm{H}, 3.47 ; \mathrm{N}, 11.14$; found $\mathrm{C}$, 66.30; $\mathrm{H}, 3.44 ; \mathrm{N}, 11.05$.

4.1.3.14. 2',4'-Difluoro-4-hydroxy-N'-[(2,2-difluoro-1,3-benzodioxol5-yl)methylidene] biphenyl-3-carbohydrazide (3n). White solid; Yield: 82\%; HPLC: $t_{R}$ (min.): 9.64; Mp 244-245 ${ }^{\circ} \mathrm{C}$; FTIR $\left(\mathrm{cm}^{-1}\right)$ : $3244(\mathrm{O}-\mathrm{H} \& \mathrm{~N}-\mathrm{H}), 3080,3024$ (=C-H arom.), 1641 ( $\mathrm{C}=\mathrm{O}), 1583$ $(\mathrm{C}=\mathrm{N}) ;{ }^{1} \mathrm{H}$ NMR $(300 \mathrm{MHz}),\left(\mathrm{DMSO}-d_{6} / \mathrm{TMS}\right) \delta \mathrm{ppm}: 7.11(\mathrm{~d}, 1 \mathrm{H}$, $\left.J=8.5 \mathrm{~Hz}, \mathrm{H}_{5}\right) ; 7.22\left(\mathrm{t}, 1 \mathrm{H}, \mathrm{H}_{11}\right) ; 7.38\left(\mathrm{t}, 1 \mathrm{H}, \mathrm{H}_{9}\right) ; 7.51-7.65(\mathrm{~m}, 5 \mathrm{H}$, $\mathrm{Ar}-\mathrm{H}) ; 8.02\left(\mathrm{~s}, 1 \mathrm{H}, \mathrm{H}_{2}\right) ; 8.47(\mathrm{~s}, 1 \mathrm{H}, \mathrm{CH}=\mathrm{N}) ; 11.94(\mathrm{~s}, 2 \mathrm{H}$, $\mathrm{CO}-\mathrm{NH}-\mathrm{N}=\mathrm{CH} \& \mathrm{Ar}-\mathrm{OH}) .{ }^{13} \mathrm{C}$ NMR $(150 \mathrm{MHz})\left(\mathrm{DMSO}_{-} \mathrm{d}_{6} / \mathrm{TMS}\right)$ $\delta$ ppm: 104.93, 108.04, 110.95, 112.41, 116.95, 118.07, 124.51, 125.31, $125.45,129.97 \& 131.95 \& 133.31$ (C-F); 124.55, 131.71, 132.14, $134.52,143.83,144.42,147.33(-\mathrm{N}=\mathrm{CH}) ; 158.66 \& 160.30(\mathrm{C}-\mathrm{F})$; 159.10, 161.12. $162.80(\mathrm{C}-\mathrm{F}), 164.79^{-}(-\mathrm{C}=\mathrm{O})$; Anal. Calcd for $\mathrm{C}_{21} \mathrm{H}_{12} \mathrm{~F}_{4} \mathrm{~N}_{2} \mathrm{O}_{4}$ : C, 58.34; $\mathrm{H}, 2.80 ; \mathrm{N}, 6.48$; found $\mathrm{C}, 57.86 ; \mathrm{H}, 2.73 ; \mathrm{N}$, 6.37.

4.1.3.15. 2',4'-Difluoro-4-hydroxy- $N^{\prime}-\{[3-($ trifluoromethyl)methylidene\}biphenyl-3-carbohydrazide (3o). White solid; Yield: 92\%; HPLC: $\mathrm{t}_{\mathrm{R}}$ (min.): 9.72; Mp $221^{\circ} \mathrm{C}$; FTIR $\left(\mathrm{cm}^{-1}\right)$ : $3257(\mathrm{O}-\mathrm{H} \& \mathrm{~N}-\mathrm{H})$, 3047 ( $=\mathrm{C}-\mathrm{H}$ arom. $), 1641(\mathrm{C}=\mathrm{O}), 1608(\mathrm{C}=\mathrm{N}) ;{ }^{1} \mathrm{H}$ NMR $(500 \mathrm{MHz})$, (DMSO-d $d_{6} /$ TMS) $\delta$ ppm: $7.09\left(\mathrm{~d}, 1 \mathrm{H}, J=8.7 \mathrm{~Hz}, \mathrm{H}_{5}\right) ; 7.20\left(\mathrm{t}, 1 \mathrm{H}, \mathrm{H}_{11}\right)$; 7.35 (t, 1H, H9); 7.57-8.04 (m, 6H, Ar-H); $8.08\left(\mathrm{~s}, 1 \mathrm{H}, \mathrm{H}_{2}\right) ; 8.54(\mathrm{~s}$, $1 \mathrm{H}, \mathrm{CH}=\mathrm{N}) ; 12.02(\mathrm{~s}, 2 \mathrm{H}, \mathrm{CO}-\mathrm{NH}-\mathrm{N}=\mathrm{CH} \& \mathrm{Ar}-\mathrm{OH})$ (exchangeable with $\mathrm{D}_{2} \mathrm{O}$ ). ${ }^{13} \mathrm{C}$ NMR (125 MHz) (DMSO-d 6 TMS) $\delta$ ppm: 105.16, $112.78,117.34,118.25,121.45 \& 123.62 \& 125.78 \& 127.95 \quad\left(-{ }_{-} F_{3}\right)$; $123.87,124.76,125.86,127.23,129.83,130.28,130.79,131.89,13 \overline{2} .38$, 134.79, 135.97, $147.71(-\mathrm{N}=\mathrm{CH}) ; 158.74 \& 160.71(\mathrm{C}-\mathrm{F}), 159.02$, 161.22, $163.18(\mathrm{C}-\mathrm{F}), 165.05(-\overline{\mathrm{C}}=\mathrm{O})$. HRMS $(\mathrm{EI}, \mathrm{m} / \mathrm{z})$ : monoisotopic mass for $\mathrm{C}_{21} \mathrm{H}_{13} \mathrm{~F}_{5} \mathrm{~N}_{2} \mathrm{O}_{2}$ (Calcd./Found): 420.0897/420.0894; Anal. Calcd for $\mathrm{C}_{21} \mathrm{H}_{13} \mathrm{~F}_{5} \mathrm{~N}_{2} \mathrm{O}_{2}$ : C, 60.01; $\mathrm{H}, 3.12 ; \mathrm{N}, 6.66$; found $\mathrm{C}, 59.69 ; \mathrm{H}$, $3.45 ; \mathrm{N}, 6.57$.

4.1.3.16. 2',4'-Difluoro-4-hydroxy- $N^{\prime}-\{[4-($ trifluoromethyl)phenyl $]$ methylidene biphenyl-3-carbohydrazide (3p). Yellow solid; Yield: 81\%; HPLC: $t_{R}$ (min.): 9.69; Mp $260{ }^{\circ} \mathrm{C}$; FTIR $\left(\mathrm{cm}^{-1}\right): 3261$ $(\mathrm{O}-\mathrm{H} \& \mathrm{~N}-\mathrm{H}), 3074,3049$ (=C-H arom.), $1633(\mathrm{C}=\mathrm{O}), 1616(\mathrm{C}=\mathrm{N})$; ${ }^{1} \mathrm{H}$ NMR (300 MHz), (DMSO-d $\left.d_{6} / \mathrm{TMS}\right) \delta \mathrm{ppm}: 7.10(\mathrm{~d}, 1 \mathrm{H}, J=8.4 \mathrm{~Hz}$, $\left.\mathrm{H}_{5}\right) ; 7.22\left(\mathrm{t}, 1 \mathrm{H}, \mathrm{H}_{11}\right) ; 7.39\left(\mathrm{t}, 1 \mathrm{H}, \mathrm{H}_{9}\right) ; 7.57-7.97(\mathrm{~m}, 6 \mathrm{H}, \mathrm{Ar}-\mathrm{H}) ; 8.02$ $\left(\mathrm{s}, 1 \mathrm{H}, \mathrm{H}_{2}\right) ; 8.54(\mathrm{~s}, 1 \mathrm{H}, \mathrm{CH}=\mathrm{N}) ; 11.91(\mathrm{~s}, 1 \mathrm{H}, \mathrm{Ar}-\mathrm{OH}) 12.04(\mathrm{~s}, 1 \mathrm{H}$, $\mathrm{CO}-\mathrm{NH}-\mathrm{N}=\mathrm{CH}$ ); Anal. Calcd for $\mathrm{C}_{21} \mathrm{H}_{13} \mathrm{~F}_{5} \mathrm{~N}_{2} \mathrm{O}_{2}: \mathrm{C}, 60.01 ; \mathrm{H}, 3.12 ; \mathrm{N}$ 6.66 ; found C, 59.58; $\mathrm{H}, 3.01 ; \mathrm{N}, 6.64$.
4.1.3.17. 2',4'-Difluoro-4-hydroxy- $N^{\prime}-[($ napthalen-1-yl)methylidene] biphenyl-3-carbohydrazide (3r). Yellow solid; Yield: 80\%; HPLC: $t_{R}$ (min.): 9.41; Mp 266-268 ${ }^{\circ} \mathrm{C}$; FTIR $\left(\mathrm{cm}^{-1}\right): 3265(\mathrm{O}-\mathrm{H} \& \mathrm{~N}-\mathrm{H})$, 3078, 3047 (=C-H arom.), $1637(\mathrm{C}=\mathrm{O}), 1612(\mathrm{C}=\mathrm{N}) ;{ }^{1} \mathrm{H}$ NMR (300 MHz), (DMSO- $\left.d_{6} / \mathrm{TMS}\right) \delta$ ppm: $7.13\left(\mathrm{~d}, 1 \mathrm{H}, J=8.4 \mathrm{~Hz}, \mathrm{H}_{5}\right) ; 7.24$ $\left(\mathrm{t}, 1 \mathrm{H}, \mathrm{H}_{11}\right) ; 7.41\left(\mathrm{t}, 1 \mathrm{H}, \mathrm{H}_{9}\right) ; 7.60-8.95(\mathrm{~m}, 10 \mathrm{H}, \mathrm{Ar}-\mathrm{H}) ; 9.11(\mathrm{~s}, 1 \mathrm{H}$, $\mathrm{CH}=\mathrm{N}) ; 12.01(\mathrm{~s}, 2 \mathrm{H}, \mathrm{Ar}-\mathrm{OH} \& \mathrm{CO}-\mathrm{NH}-\mathrm{N}=\mathrm{CH})$; Anal. Calcd for $\mathrm{C}_{24} \mathrm{H}_{16} \mathrm{~F}_{2} \mathrm{~N}_{2} \mathrm{O}_{2}$ : C, 71.64; $\mathrm{H}, 4.01 ; \mathrm{N}, 6.96$; found $\mathrm{C}, 71.34 ; \mathrm{H}, 4.07 ; \mathrm{N}$, 6.98 .

4.1.3.18. 2',4'-Difluoro-4-hydroxy- $N^{\prime}$-[(napthalen-2-yl)methylidene] biphenyl-3-carbohydrazide (3s). Light yellow solid; Yield: 89\%; HPLC: $\mathrm{t}_{\mathrm{R}}$ (min.): 9.88; $\mathrm{Mp} 279^{\circ} \mathrm{C}$; FTIR $\left(\mathrm{cm}^{-1}\right)$ : $3244(\mathrm{O}-\mathrm{H} \& \mathrm{~N}-\mathrm{H})$, 3047, 3039 (=C-H arom.), $1651(\mathrm{C}=\mathrm{O}), 1606(\mathrm{C}=\mathrm{N}) ;{ }^{1} \mathrm{H}$ NMR (300 MHz), (DMSO-d $\left.d_{6} / \mathrm{TMS}\right) \delta \mathrm{ppm}: 7.10\left(\mathrm{~d}, 1 \mathrm{H}, J=8.4 \mathrm{~Hz}, \mathrm{H}_{5}\right) ; 7.22$ $\left(\mathrm{t}, 1 \mathrm{H}, \mathrm{H}_{11}\right) ; 7.38\left(\mathrm{t}, 1 \mathrm{H}, \mathrm{H}_{9}\right) ; 7.57-8.05(\mathrm{~m}, 9 \mathrm{H}, \mathrm{Ar}-\mathrm{H}) ; 8.25(\mathrm{~s}, 1 \mathrm{H}$, $\left.\mathrm{H}_{2}\right) ; 8.61(\mathrm{~s}, 1 \mathrm{H}, \mathrm{CH}=\mathrm{N}) ; 11.95(\mathrm{~s}, 1 \mathrm{H}, \mathrm{Ar}-\mathrm{OH} \& \mathrm{CO}-\mathrm{NH}-\mathrm{N}=\mathrm{CH}) .{ }^{13} \mathrm{C}$ NMR $(150 \mathrm{MHz})$ (DMSO-d 6 TMS) $\delta \mathrm{ppm:} \mathrm{104.93,} \mathrm{112.49,} \mathrm{116.99,}$ 118.06, 123.19, 124.52, 127.29, 127.76, 128.27, 128.86, 129.04, 129.41, $129.54,132.15,132.21,132.27,133.27,134.32,134.54,149.32(-\mathrm{N}=$ $\mathrm{CH}), 158.67 \& 160.14,159.04,160.31 \& 162.77,164.87(-\mathrm{C}=\mathrm{O})$. DARTMS; (m/z, Calcd/Found): 403.1253/403.1258 $\left[\mathrm{C}_{24} \mathrm{H}_{16} \overline{\mathrm{F}}_{2} \mathrm{~N}_{2} \mathrm{O}_{2}+\mathrm{H}\right]^{+}$; 805.2432/805.2445 $\left[2\left(\mathrm{C}_{24} \mathrm{H}_{16} \mathrm{~F}_{2} \mathrm{~N}_{2} \mathrm{O}_{2}\right)+\mathrm{H}\right]^{+}$; Anal. Calcd for $\mathrm{C}_{24} \mathrm{H}_{16} \mathrm{~F}_{2} \mathrm{~N}_{2} \mathrm{O}_{2}$ : C, 71.64; $\mathrm{H}, 4.01 ; \mathrm{N}, 6.96$; found $\mathrm{C}, 71.64 ; \mathrm{H}, 3.82 ; \mathrm{N}$, 6.86 .

4.1.3.19. 2',4'-Difluoro-4-hydroxy-N'-[(3-phenoxyphenyl)methylidene]biphenyl-3-carbohydrazide (3t). Yellow solid; Yield: 85\%; HPLC: $t_{\mathrm{R}}$ (min.): 9.21; Mp $198{ }^{\circ} \mathrm{C}$; FTIR $\left(\mathrm{cm}^{-1}\right)$ : $3257(\mathrm{O}-\mathrm{H} \& \mathrm{~N}-\mathrm{H})$, 3064, 3020 (=C-H arom.), 1635 ( $\mathrm{C}=\mathrm{O}), 1614(\mathrm{C}=\mathrm{N}) ;{ }^{1} \mathrm{H}$ NMR (300 MHz), (DMSO- $\left.d_{6} / \mathrm{TMS}\right) \delta$ ppm: 6.98-7.64 (m, 14H, Ar-H); 8.01 $\left(\mathrm{s}, 1 \mathrm{H}, \mathrm{H}_{2}\right) ; 8.44(\mathrm{~s}, 1 \mathrm{H}, \mathrm{CH}=\mathrm{N}) ; 11.82(\mathrm{~s}, 1 \mathrm{H}, \mathrm{Ar}-\mathrm{OH}) ; 11.94(\mathrm{~s}, 1 \mathrm{H}$, $\mathrm{CO}-\mathrm{NH}-\mathrm{N}=\mathrm{CH}$ ); Anal. Calcd for $\mathrm{C}_{26} \mathrm{H}_{18} \mathrm{~F}_{2} \mathrm{~N}_{2} \mathrm{O}_{3}$ : C, 70.26; $\mathrm{H}, 4.13 ; \mathrm{N}$, 6.32; found C, 69.90; $\mathrm{H}, 4.13 ; \mathrm{N}, 6.32$.

\subsection{Biological studies}

\subsubsection{Cell culture}

Huh7/Rep-Feo1b and Huh7.5-FGR-JC1-Rluc2A replicon reporter cells were cultured in Dulbecco's modified Eagle's medium (DMEM) containing 10\% fetal calf serum, $5 \%$ antibiotic and $0.5 \mathrm{mg} /$ $\mathrm{mL}$ G418. All cells were cultured at $37{ }^{\circ} \mathrm{C}$ and $5 \% \mathrm{CO}_{2}$.

\subsubsection{HCV replicon based luciferase reporter assays}

The Huh7/Rep-Feo1b and Huh7.5-FGR-JC1-Rluc2A replicon reporter cells have been described previously $[20,21]$. To evaluate the anti-HCV activity of the compounds, HCV replicon reporter cells were seeded in 96 well plate at a confluence of $1 \times 10^{4}$ cells/well. Eight hours post seeding, the cells were treated with the individual compounds ( $100 \mu \mathrm{M} /$ well) or equivalent amounts of DMSO for $42 \mathrm{~h}$. Cell viability was measured in the parental Huh7.5 cells by the colorimetric MTS assay employing the CellTiter 96AQueous One Solution assay reagent (Promega, USA). The anti-HCV activity of the compounds was evaluated as the relative levels of the luciferase signals in compound treated cells versus DMSO controls.

\subsubsection{NS5B inhibition assay}

The biological activity of the compounds against NS5B polymerase were evaluated in a reaction buffer containing $20 \mathrm{mM}$ Tris- $\mathrm{HCl}$ ( $\mathrm{pH} 7.0$ ), $100 \mathrm{mM} \mathrm{NaCl}, 100 \mathrm{mM}$ sodium glutamate, $0.1 \mathrm{mM}$ DTT, $0.01 \%$ BSA, $0.01 \%$ Tween-20, 5\% glycerol, $20 \mathrm{U} / \mathrm{mL}$ of RNase Out, $0.25 \mu \mathrm{M}$ of polyrA/U12, $25 \mu \mathrm{M}$ UTP, $2 \mu \mathrm{Ci}$ [alpha- ${ }^{32} \mathrm{P}$ ]UTP, $300 \mathrm{ng}$ of NS5BC $\Delta 21$ and $1.0 \mathrm{mM} \mathrm{MnCl} 2$ with or without inhibitors $(100 \mu \mathrm{M})$ in a total volume of $25 \mu \mathrm{L}$ for $1 \mathrm{~h}$ at $30^{\circ} \mathrm{C}$ as previously described $[26,27]$. Reactions were terminated by the addition of 
ice-cold 5\% (v/v) trichloroacetic acid (TCA) containing $0.5 \mathrm{mM}$ pyrophosphate. Reaction products were precipitated on GF-B filters and quantified on a liquid scintillation counter. NS5B activity in the presence of DMSO control was set at $100 \%$ and that in the presence of the compounds was determined relative to this control.

\subsubsection{Anticancer activity against hepatocelluler cell lines}

4.2.4.1. Cell culture. Human liver cancer cell lines were grown in the standard growth medium $(2 \mathrm{mM}$ L-glutamine, $0.1 \mathrm{mM}$ nonessential amino acids, 100 units $/ \mathrm{mL}$ penicillin, $100 \mathrm{lg} / \mathrm{mL}$ streptomycin, 10\% FCS in DMEM (Gibco, Invitrogen) or RPMI (Gibco, Invitrogen) and incubated at $37{ }^{\circ} \mathrm{C}$ under $5 \% \mathrm{CO}_{2}$.

4.2.4.2. Sulforhodamine B (SRB) assay for cytotoxicity screening. Human liver cancer cells were cultured in 96-well plates (1000-3000 cell/well) and for $24 \mathrm{~h}$. They were treated with increasing concentrations of the compounds $(2.5-40 \mu \mathrm{M})$. Cell were washed with $1 \times \mathrm{PBS}\left(\mathrm{CaCl}_{2^{-}}, \mathrm{MgCl}_{2}\right.$-free) (Gibco, Invitrogen) at the end of $72 \mathrm{~h}$ incubation period. Fixation was performed using $10 \%(\mathrm{v} / \mathrm{v})$ trichloroacetic acid (MERCK). Finally, $0.4 \%(\mathrm{~m} / \mathrm{v})$ of sulforhodamine (Sigma-Aldrich) in $1 \%$ acetic acid solution was added to each well for staining process. The bound sulforhodamine B was then solubilized using $10 \mathrm{mM}$ Tris-base. The absorbance values were obtained at $515 \mathrm{~nm}$.

4.2.4.3. Hoechst stain. Human liver cancer cells (Huh7 and Mahlavu) were inoculated in 6 -well plates for $24 \mathrm{~h}$. The cells were treated with $\mathrm{IC}_{50}$ concentrations of the compounds for $72 \mathrm{~h}$. Hoescht 33258 (Sigma-Aldrich) staining was used to determine nuclear condensation. Cells were fixed with $1 \mathrm{~mL}$ of cold methanol and the samples were incubated with $3 \mathrm{lg} / \mathrm{mL}$ of Hoescht, and examined under fluorescent microscopy $(40 \times)$.

4.2.4.4. Western blotting. Human liver cancer cells were cultured in $100 \mathrm{~mm}$ culture dish. $24 \mathrm{~h}$ later, growth medium was replaced and cells were treated with $\mathrm{IC}_{50}$ concentrations of the compounds or DMSO controls. At the end of $72 \mathrm{~h}$ incubation, samples were scraped and collected for western blot analysis. Anti-PARP antibody (Cell Signaling, 9532) and anti- $\beta$-actin antibody (Sigma, 5441) were used as primary antibodies. Anti-rabbit (6154) and anti-mouse (0168) secondary antibodies were used.

4.2.4.5. Cell cycle analysis. Cells were treated with $\mathrm{IC}_{50}$ concentrations of the compounds or $72 \mathrm{~h}$. Then samples were stained with propidium iodide which binds to DNA and analyzed with MUSE Cell Cycle analyzer kit.

\section{Acknowledgments}

This work was supported by The Scientific and Technical Research Council of Turkey (TÜBITAK), Research Fund Project Number: 112S013. Anti-HCV studies were supported by funds from the UMDNJ Health Foundation to N.K. -B. (Project number: 105110). Diflunisal was supplied by Sanovel Pharmaceutical Industry Inc. The authors are grateful to Jürgen Gross from the Institute of
Organic Chemistry, University of Heidelberg, for his generous help in obtaining HR-EI and DART-MS mass spectra of the synthesized compounds. We acknowledge Dr. Hengli Tang for generously sharing the Huh7.5-FGR-JC1-Rluc2A replicon reporter cells.

\section{Appendix A. Supplementary data}

Supplementary data related to this article can be found at http:// dx.doi.org/10.1016/j.ejmech.2015.10.041.

\section{References}

[1] Q.L. Choo, K.H. Richman, J.H. Han, K. Berger, C. Lee, C. Dong, C. Gallegos, D. Coit, R. Medina-Selby, P.J. Barr, et al., Proc. Natl. Acad. Sci. U. S. A. 88 (1991) 2451-2455

[2] Y. Tanji, M. Hijikata, Y. Hirowatari, K. Shimotohno, J. Virol. 68 (1994) $8418-8422$

[3] P. Leyssen, E. De Clercq, J. Neyts, Clin. Microbiol. Rev. 13 (2000) 67-82.

[4] K. Garber, Nat. Biotechnol. 29 (2011) 963-966.

[5] C. Rice, Nature 474 (2011) S8.

[6] C. Sheridan, Nat. Biotechnol. 29 (2011) 553-554.

[7] C. Sheridan, Nat. Biotechnol. 32 (2014) 3-5.

[8] D.L. Wyles, Top. Antivir. Med. 20 (2012) 139-145.

[9] N. Palanisamy, A. Danielsson, C. Kokkula, H. Yin, K. Bondeson, L. Wesslen, A.S. Duberg, J. Lennerstrand, Antivir. Res. 99 (2013) 12-17.

[10] Ş.G. Küçükgüzel, A. Mazi, F. Şahin, S. Oztürk, J.P. Stables, Eur. J. Med. Chem. 38 (2003) 1005-1013.

[11] Ş.G. Küçükgüzel, A. Kocatepe, E. De Clercq, F. Şahin, M. Güllüce, Eur. J. Med Chem. 41 (2006) 353-359.

[12] S.G. Küçükgüzel, İ. Küçükgüzel, E. Tatar, S. Rollas, F. Sahin, M. Güllüce, E. De Clercq, L. Kabasakal, Eur. J. Med. Chem. 42 (2007) 893-901.

[13] N. Kaushik-Basu, A. Bopda-Waffo, A. Basu, Y. Chen, T.T. Talele, S.G. Küçükgüzel, Front. Biosci. 13 (2008) 3857-3868.

[14] S. Aydın, N. Kaushik-Basu, S. Özbaş-Turan, J. Akbuğa, P. Mega Tiber, O. Orun, K.R. Gurukumar, A. Basu, Ş.G. Küçükgüzel, Lett. Drug Des. Discov. 11 (2014) $121-131$.

[15] G. Zhong, J. Hu, K. Zhao, L. Chen, W. Hu, M. Qiu, Bioorg. Med. Chem. Lett. 19 (2009) 516-519.

[16] P. Çıkla, D. Özsavcı, Ö. Bingöl-Özakpınar, A. Şener, Ö. Çevik, S. Özbaş-Turan, J. Akbuğa, F. Sahin, S.G. Küçükgüzel, Arch. Pharm. 346 (2013) 367-379.

[17] P. Çıkla, E. Tatar, İ. Küçükgüzel, F. Şahin, D. Yurdakul, A. Basu, R. Krishnan, D. Brian Nichols, N. Kaushik-Basu, Ş.G. Küçükgüzel, Med. Chem. Res. 22 (2013) 5685-5999.

[18] S. Rollas, S.G. Küçükgüzel, Molecules 12 (2007) 1910-1939.

[19] S. Aydın, N. Kaushik-Basu, P. Arora, A. Basu, D.B. Nichols, T.T. Talele Ş.G. Küçükgüzel, Marmara Pharm. J. 17 (2013) 26-34.

[20] K. Kim, K.H. Kim, H.Y. Kim, H.K. Cho, N. Sakamoto, J. Cheong, FEBS Lett. 584 (2010) 707-712.

[21] D.B. Nichols, G. Fournet, K.R. Gurukumar, A. Basu, J.C. Lee, N. Sakamoto F. Kozielski, I. Musmuca, B. Joseph, R. Ragno, N. Kaushik-Basu, Eur. J. Med. Chem. 49 (2012) 191-199.

[22] Y. Sekine-Osajima, N. Sakamoto, M. Nakagawa, Y. Itsui, M. Tasaka, Y. Nishimura-Sakurai, C.H. Chen, G. Suda, K. Mishima, Y. Onuki, M. Yamamoto, S. Maekawa, N. Enomoto, T. Kanai, K. Tsuchiya, M. Watanabe, Hepatol. Res. Off. J. Jpn. Soc. Hepatol. 39 (2009) 60-69.

[23] I. Kucukguzel, G. Satilmis, K.R. Gurukumar, A. Basu, E. Tatar, D.B. Nichols, T.T. Talele, N. Kaushik-Basu, Eur. J. Med. Chem. 69 (2013) 931-941.

[24] I.A. Andreev, D. Manvar, M.L. Barreca, D.S. Belov, A. Basu, N.L. Sweeney, N.K. Ratmanova, E.R. Lukyanenko, G. Manfroni, V. Cecchetti, D.N. Frick, A. Altieri, N. Kaushik-Basu, A.V. Kurkin, Eur. J. Med. Chem. 96 (2015) 250-258.

[25] P. Çıkla-Süzgün, N. Kaushik-Basu, A. Basu, P. Arora, T.T. Talele, I. Durmaz R. Cetin-Atalay, S.G. Kucukguzel, J. Enzyme Inhib. Med. Chem. 30 (2015) $778-785$.

[26] L. Tomei, R.L. Vitale, I. Incitti, S. Serafini, S. Altamura, A. Vitelli, R. De Francesco J. Gen. Virol. 81 (2000) 759-767.

[27] T. Kashiwagi, K. Hara, M. Kohara, K. Kohara, J. Iwahashi, N. Hamada H. Yoshino, T. Toyoda, Biochem. Biophys. Res. Commun. 290 (2002) 1188-1194. 